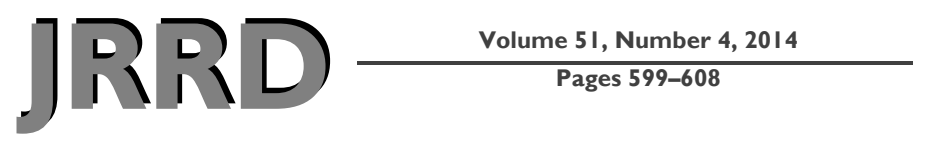

\title{
Identifying position, visibility, dimensions, and angulation of the ear
}

\author{
Kasim Mohamed, MDS; ${ }^{*}$ Jayanth Christian, MDS; Karthigeyan Jeyapalan, MDS; Shanmuganathan Natarajan, \\ MDS; Fathima Banu, MDS; Padmanabhan T. Veeravalli, MDS \\ Department of Prosthodontics, Sri Ramachandra University, Tamilnadu, India
}

\begin{abstract}
We selected 254 subjects between the ages of 18 and $30 \mathrm{yr}$ to assess the ear position, angulations of the ear in relation to the nose, visibility from the frontal view, and dimensions of the ear by using various anthropometric points of the face. Subjects were divided into four groups based on facial form. A reference plane indicator, facial topographical measurements, metal ruler, and digital photography were used. While considering the position of the ear, in all facial forms except square tapering, the most samples showed a tendency for the subaurale being in line with subnasale. Regression analysis showed a tendency to subnasale distance is the most dependent variable with length of the ear kept as a constant predictor, while both interalar distance and exocanthion to endocanthion distance correlate highly significantly to the width of the ear. In all subjects, the visibility of the ear when viewed from the front was an average of $1.5 \mathrm{~mm}$. Regardless of facial form, ear angulation was generally less than nose angulation.
\end{abstract}

Key words: anthropometry, auricular prosthesis, ear angulation, ear dimensions, ear position, ear visibility, facial forms, facial topography, maxillofacial, reference plane indicator.

\section{INTRODUCTION}

Proportional evaluation of the face has its origin in the 17th and 18th centuries in the neoclassical canons of facial proportion by artists and anatomists [1]. Many Renaissance artists believed that facial beauty was rooted in balanced proportions and facial symmetry [2]. The relationship between size and proportion of different facial measurements is considered to affect the perception of aesthetics. The growth of prosthodontics has enabled the restoration of patients with maxillofacial defects. An important aspect of successful rehabilitation is the positioning of any prosthesis on the face [3]. The ear prosthesis presents several challenges to the clinician. Regardless of the treatment plan selected for unilaterally missing ear, the existing ear's dimensions, position, level, and prominence must be measured to predict the seating and shaping of the final ear prosthesis [4], but no such guide exists for bilateral missing ear. To overcome this situation, reliable techniques are required wherein facial measurements could be used as a guide during fabrication of a prosthesis. Manual anthropometry, two-dimensional photography, and three-dimensional photogrammetry were the three most widely used methods for facial measurements [5]. Anthropometry has been shown to be useful in orthodontic research and in reconstructive surgery, where the soft tissue morphology of the face can be studied more reliably than from radiographs [6]. Currently, more than 20 landmarks and parameters are being used in the medical and dental professions for facial measurements to correlate with ear landmarks. In addition, use of a reference plane is also considered to be critical in planning the position of the prosthetic ear [3]. The use of anthropometric measurements coupled with an established reference

\footnotetext{
*Address all correspondence to Kasim Mohamed, MDS; Department of Prosthodontics, Faculty of Dental Science, Sri Ramachandra University, Porur, Chennai 600116, Tamilnadu, India; +0091-9790880945.
}

Email: mohamedkasim9@yahoo.com

http://dx.doi.org/10.1682/JRRD.2013.06.0132 
plane will help in more accurately determining the prosthetic site. This technique seemed to be more accurate than the use of anthropometric points alone [3]. Recently, computerized tomography, magnetic resonance imaging, and laser scanning techniques have also been used to measure the dimensions and position of the ear [3-4]. Studies with comprehensive guidance in designing bilateral ear prostheses are limited to date. The present study assessed ear position with a reference plane indicator, angulations of the ear in relation to nose, visibility from the frontal view, and dimensions of the ear by using various anthropometric points of the face.

\section{METHODS}

We selected 254 subjects of Southeast Asian origin, both male and female because sex-dependent differences in adolescents and young adults are minimal [7]. The subjects were selected so as to cover four facial form types as postulated by Leon Williams' classification (square, square tapering, ovoid, and tapering) [8]. To minimize the effect of aging on the facial proportion, subjects were between the ages of 18 and 30 yr [7,9-10]. Care was taken to avoid subjects with gross facial asymmetries, history of facial trauma and surgery, and mixed parental ethnicity. Convenience sampling was used for the selection of the sample.

Subjects were divided into four groups based on facial form by the concurrence of two experienced prosthodontists, and facial measurements were recorded using anthropometric points of the face. Detailed descriptions of anthropometric points are diagrammatically represented in Figure 1. For vertical/horizontal measurement of the face and identification of ear angulation, neoclassical canons were also used. For standardization, only the right ear was used to measure the dimensions, visibility, and angulation because, according to Barut and Aktunc [11], dimensions differ between the right and left ears. To identify the position of the ear, a specially designed reference plane-indicating device was used. This device, consisting of a metal frame with two metallic rulers attached, was designed to determine the superior-inferior positioning of the ear (Figure 2).

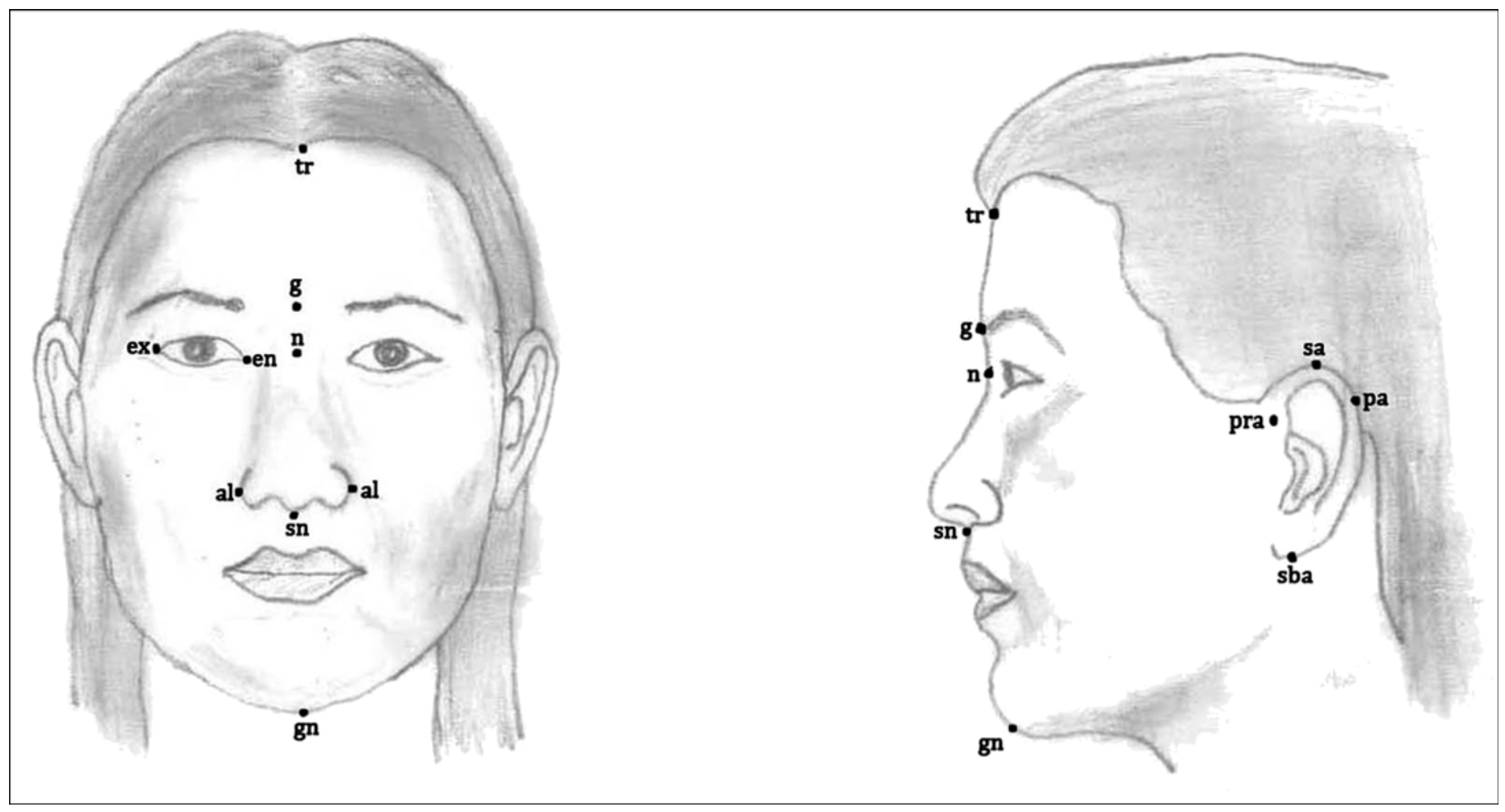

Figure 1.

Anthropometric points of face. $\mathrm{al}=$ alar, en = endocanthion, ex = exocanthion, $\mathrm{g}=$ glabella, $\mathrm{gn}=$ gnathion, $\mathrm{n}=$ nasion, pa $=$ postaurale, pra $=$ preaurale, $\mathrm{sa}=$ superaurale, $\mathrm{sba}=$ subaurale, $\mathrm{sn}=$ subnasale, $\mathrm{tr}=$ trichion. 


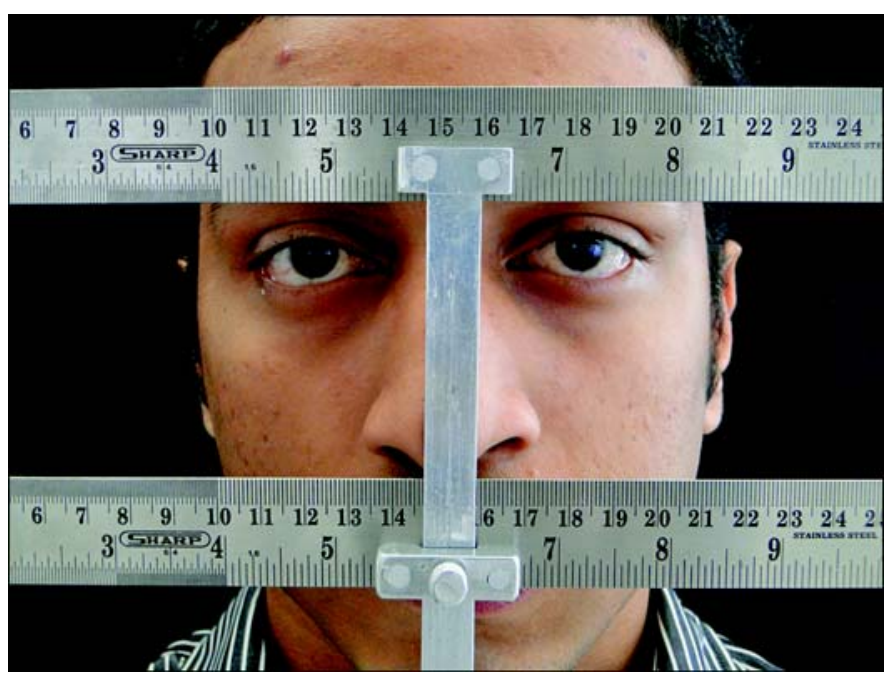

Figure 2.

Reference plane indicator.

The two rulers were positioned parallel to each other with the first ruler fixed. The distance between the two rulers could be adjusted with the help of a thumb screw attached to the second ruler. A chin rest was attached below the second ruler. The distance between the second ruler and the chin rest was also adjustable with the help of a thumb screw. All measurements were made with the chin resting in the chin rest. Additionally, all subjects were seated in a chair facing straight and with the back upright. The operator was approximately $2 \mathrm{ft}$ ahead and seated directly in front of the subject. The operator's eye level was adjusted to coincide with that of the subject. Operator and subject positions were verified by another investigator. Not more than 15 samples were recorded at a time to avoid operator fatigue.

For recording ear position, a line was drawn passing through the glabella parallel to the interpupillary line. A second line was drawn passing through the subnasale parallel to the interpupillary line. The lengths of these lines were $2 \mathrm{~cm}$ for ease of visibility. The superior-inferior relationship of the ear (superaurale and subaurale) to the previously stated two lines was noted. The reference plane indicator described earlier was used for this purpose. The reference plane indicator was placed in front of the patient's face and the inferior surface of the first ruler was made to coincide with the line passing through the glabella. The chin rest was adjusted so that the subject rested the chin comfortably. Care was taken to see that the relationship between the inferior surface of the first ruler and the line passing through the glabella did not change. The second ruler was then adjusted so that the superior edge of the ruler coincided with the line passing through the subnasale. The relationship of the ear with the glabella and subnasale was observed to see whether the position of the ear could be classified in one or more of the following categories:

A. Ear lies within the glabella and subnasale.

B. Subaurale is in line with the subnasale.

C. Superaurale is in line with the glabella.

D. Superaurale is above the level of the glabella.

E. Subaurale is below the level of the subnasale.

The second step was to measure the dimensions of the ear. All variables were measured twice by the same investigator using a digital vernier caliper (model 2061, Mitutoyo Digimatic Caliper; Kawasaki, Japan), and the average of the measurements was recorded in centimeters. The distance between superaurale and subaurale was considered as the length of the ear. The distance between preaurale and postaurale was considered as the width of the ear (Figure 3(a)). To assess the length and width of the ear, the following facial topographical measurements were used:

1. To correlate the length with the facial parameters, the following were recorded (Figure 3(b)):

(a) Nasion to subnasale $=$ nasal height.

(b) Glabella to subnasale = midfacial height .

(c) Glabella to trichion = forehead height.

(d) Subnasale to gnathion = lower facial height measured when mandible is at rest position.

2. To correlate the width of the ear with the facial parameters, the following were recorded (Figure 3(c)):

(a) The interalar distance $=$ nasal width.

(b) Endocanthion to exocanthion = eye fissure width.

The length and width of the ear were kept as constants and compared with the other variables. In the case of the length of the ear, the variables taken into consideration were nasion to subnasale, glabella to subnasale, glabella to trichion, and subnasale to gnathion distances. For the width of the ear, the interalar distance and endocanthion to exocanthion distance were measured. Regression model by backward elimination method and Pearson correlation were used to assess the relation between the variables with SPSS version 16.0 (IBM Corporation; Armonk, New York).

Visibility of the ear from the frontal view was evaluated by positioning all subjects and the operator as described for determining the position of the ear. A metallic ruler was placed anteriorly in contact with the skin just anterior to the preaurale with its edge perpendicular to the 

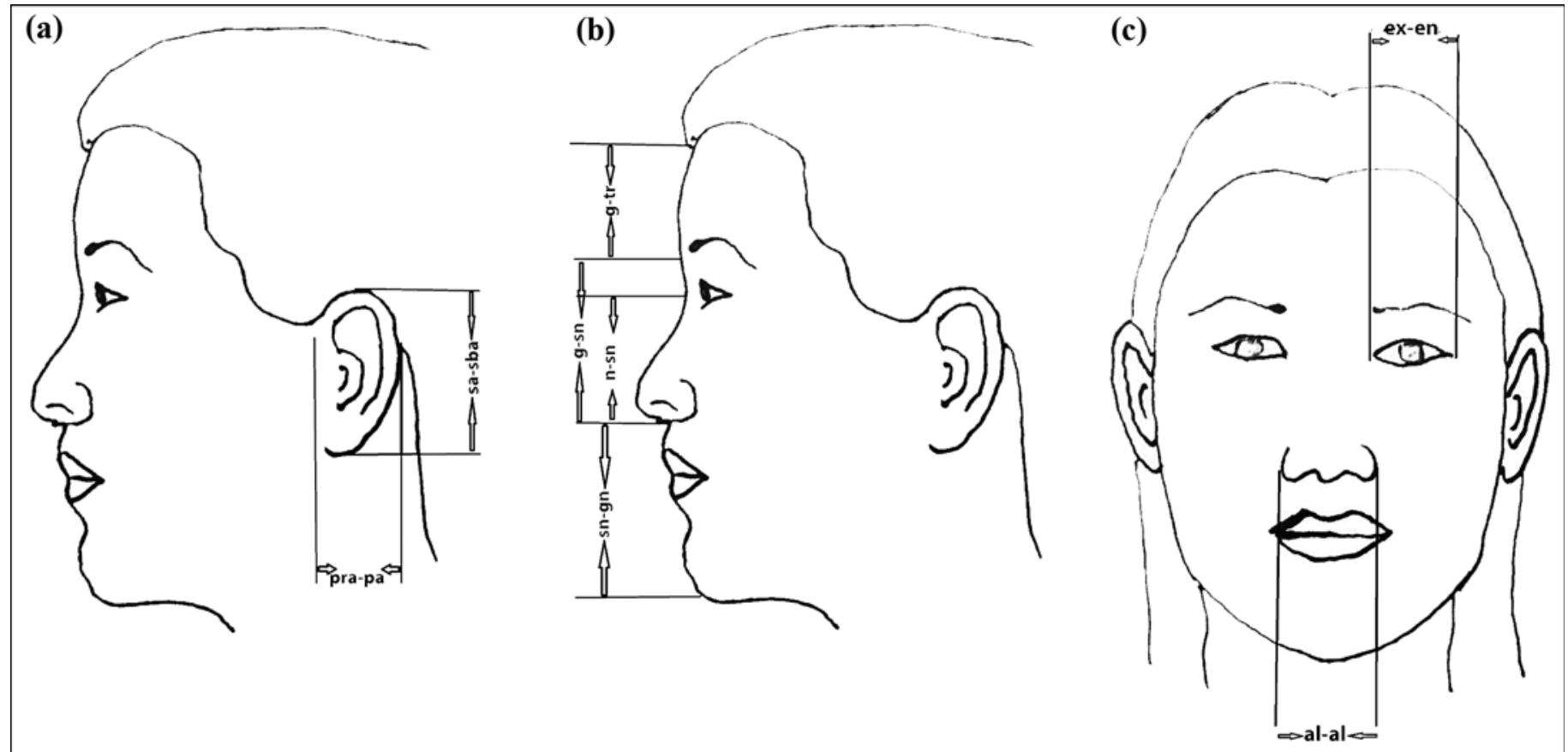

Figure 3.

(a) Measurement of length and width of ear. (b) Parameters correlating with length of ear. (c) Parameters correlating with width of ear. al-al = interalar distance, en = endocanthion, ex = exocanthion, $\mathrm{g}=$ glabella, $\mathrm{gn}=$ gnathion, $\mathrm{n}=\mathrm{nasion}, \mathrm{pa}=\mathrm{postaurale}, \mathrm{pra}=$ preaurale, $\mathrm{sa}=$ superaurale, $\mathrm{sba}=$ subaurale, $\mathrm{sn}=$ subnasale, $\mathrm{tr}=$ trichion.

lateral surface of the face (Figure 4). Measurements were made with biocular vision. The extension of the ear was measured in centimeters up to the lateral-most portions.

Finally, the angulation of the ear was compared with the angulation of the nose by making a profile digital photograph (DSLR D7100, Nikon; Tokyo, Japan) for each subject. A line was drawn on the photograph passing through the long axis of the ear and the nose (Figure 5). The angulation of these lines with respect to the vertical axis was measured. The samples were divided into three groups: those with ear angulation less than that of the nose, those with both angulations almost equal, and those with angulation of the ear more than that of nose. The percentages for each individual group were calculated and tabulated. The data were analyzed separately for the four facial forms.

\section{RESULTS}

The position of the ear was analyzed using a reference plane indicator for all four facial forms. The relationship of the ear with the glabella and subnasale was observed to see if the position of the ear could be determined. A crosstabulation analysis was done to find the maximum frequency among the five categories, as already mentioned.

In all facial forms except square tapering, the maximum number of samples showed highest frequency for $B$ (subaurale in line with subnasale) followed by E (subaurale is below level of subnasale). In the square tapering facial form, the highest number of samples showed maximum frequency for E, followed by B (Table 1).

Both regression analysis and Pearson correlation test showed similar results for length of the ear. The regression analysis results determined the most dependent variable, with the length of the ear kept as a constant. A Pearson correlation test was carried out to assess the strength of relation between the variables.

We observed high significance with subnasale to gnathion in the ovoid facial form, whereas for the square form both subnasale to gnathion and nasion to subnasale were highly significant, and in square tapering form glabella to subnasale was also highly significant. In the case of the tapering facial form, highly significant correlation 


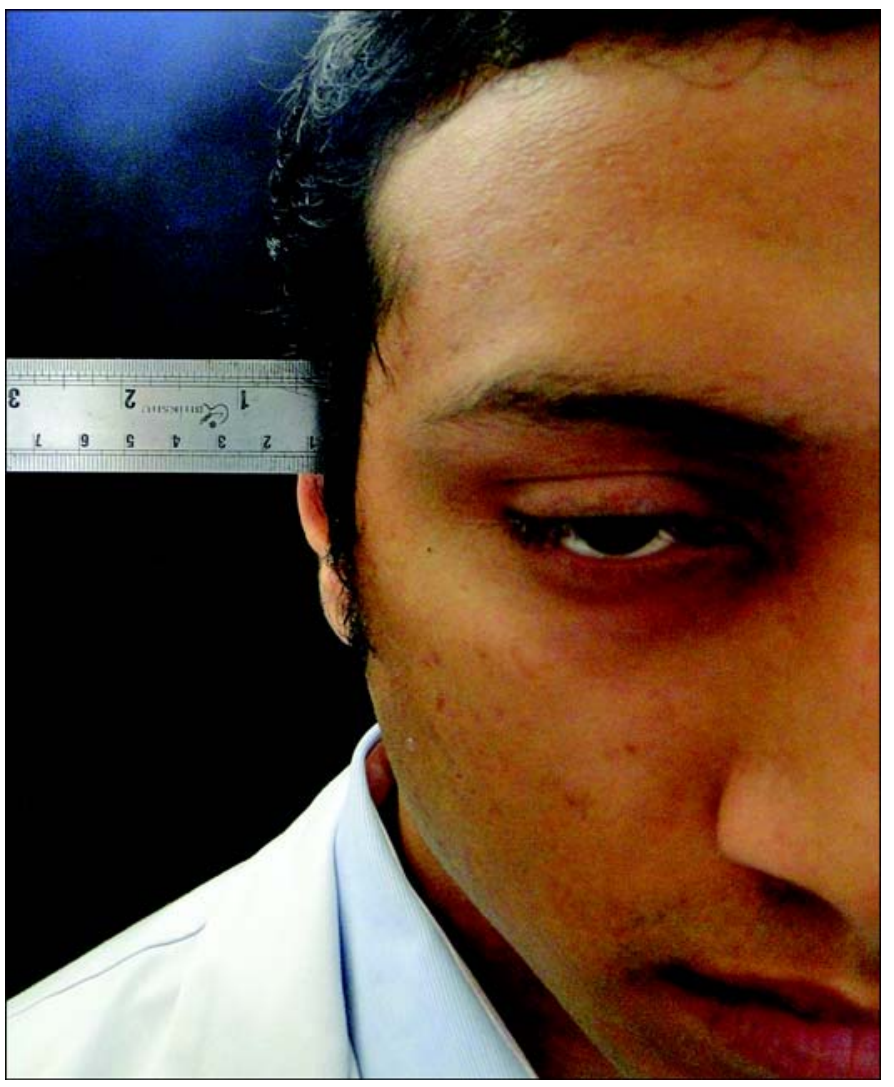

Figure 4.

Identifying visibility of ear.

was observed in glabella to subnasale and glabella to trichion, but subnasale to gnathion was not significant (Tables 2-3).

Pearson correlation test for width of the ear showed that there was highly significant correlation with both interalar distance and exocanthion to endocanthion in all facial forms (Table 4).

For visibility of the ear, the mean visibility for each group was $1.474 \pm 0.274 \mathrm{~cm}$ for ovoid forms, $1.491 \pm$ $0.258 \mathrm{~cm}$ for square faces, $1.537 \pm 0.328 \mathrm{~cm}$ for tapering facial forms, and $1.52 \pm 0.352 \mathrm{~cm}$ for square tapering facial forms. A mean visibility of approximately $1.5 \mathrm{~cm}$ can be assumed (Table 5).

In general, for all facial forms, maximum percentage of individuals showed angulation of the ear to be less than that of the nose, with an average of 87.1 percent. Those with angulation of the ear being almost equal to that of the nose were only 12.4 percent, and greater than that of the nose were 0.5 percent (Table 6).

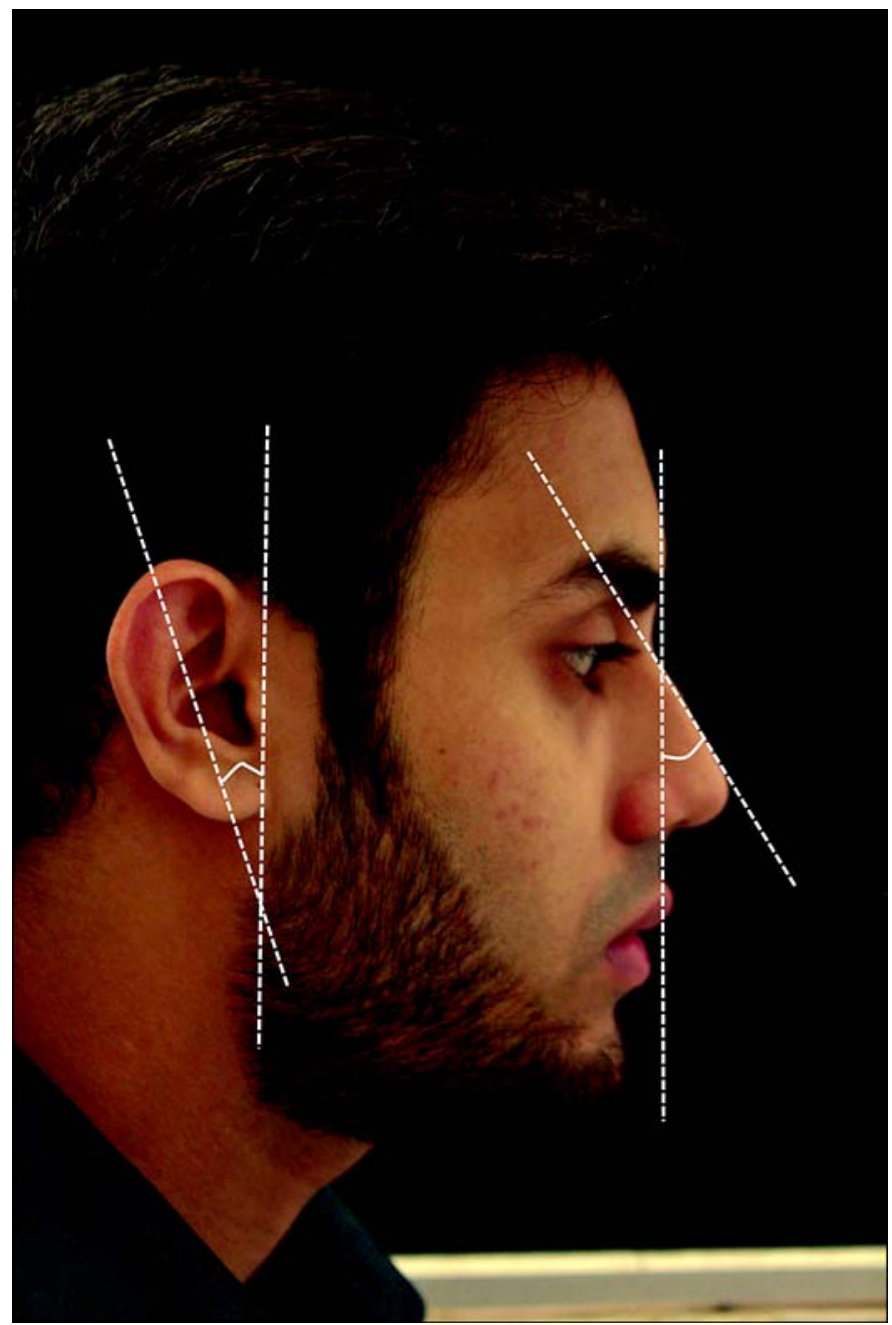

Figure 5.

Angulation of ear compared with nose.

\section{DISCUSSION}

The successful fabrication of an ear prosthesis depends not only on the technical aspect of the fabrication but also on ideal positioning, dimensions, visibility, and angulation. In the case of unilateral missing ear, these factors are easier to determine; however, in bilateral missing ears, determining these factors poses a significant challenge. The remnant of the damaged pinna serves as a guide to the maxillofacial prosthodontists in positioning a prosthetic ear, but for bilateral anotia and microtia no such guide exists. This significantly increases the difficulty of restoring such cases. Even though recently advanced techniques are used for correct placement of a prosthesis, it is 
JRRD, Volume 51, Number 4, 2014

Table 1.

Frequency distribution with percentage for position of ear.

\begin{tabular}{|c|c|c|c|c|c|c|c|c|}
\hline \multirow{2}{*}{ Category } & \multicolumn{2}{|c|}{ Ovoid Face $(N=53)$} & \multicolumn{2}{|c|}{ Square Face $(N=82)$} & \multicolumn{2}{|c|}{ Tapering Face $(N=52)$} & \multicolumn{2}{|c|}{$\begin{array}{l}\text { Square Tapering Face } \\
\qquad(N=57)\end{array}$} \\
\hline & $n$ & $\%$ & $n$ & $\%$ & $n$ & $\%$ & $n$ & $\%$ \\
\hline$\overline{\mathrm{A}}$ & 9 & 17.0 & 4 & 4.9 & 4 & 6.5 & 5 & 8.8 \\
\hline B & 20 & 37.7 & 43 & 52.4 & 29 & 46.8 & 20 & 35.1 \\
\hline $\mathrm{B}$ and $\mathrm{C}$ & 3 & 5.7 & 6 & 7.3 & 2 & 3.2 & 3 & 5.3 \\
\hline $\mathrm{C}$ & 4 & 7.5 & 5 & 6.1 & 12 & 19.4 & 6 & 10.5 \\
\hline $\mathrm{E}$ & 17 & 32.1 & 23 & 28.0 & 14 & 22.6 & 22 & 38.6 \\
\hline
\end{tabular}

Table 2.

Regression analysis for length of ear, using various forms of faces with anthrometric point.

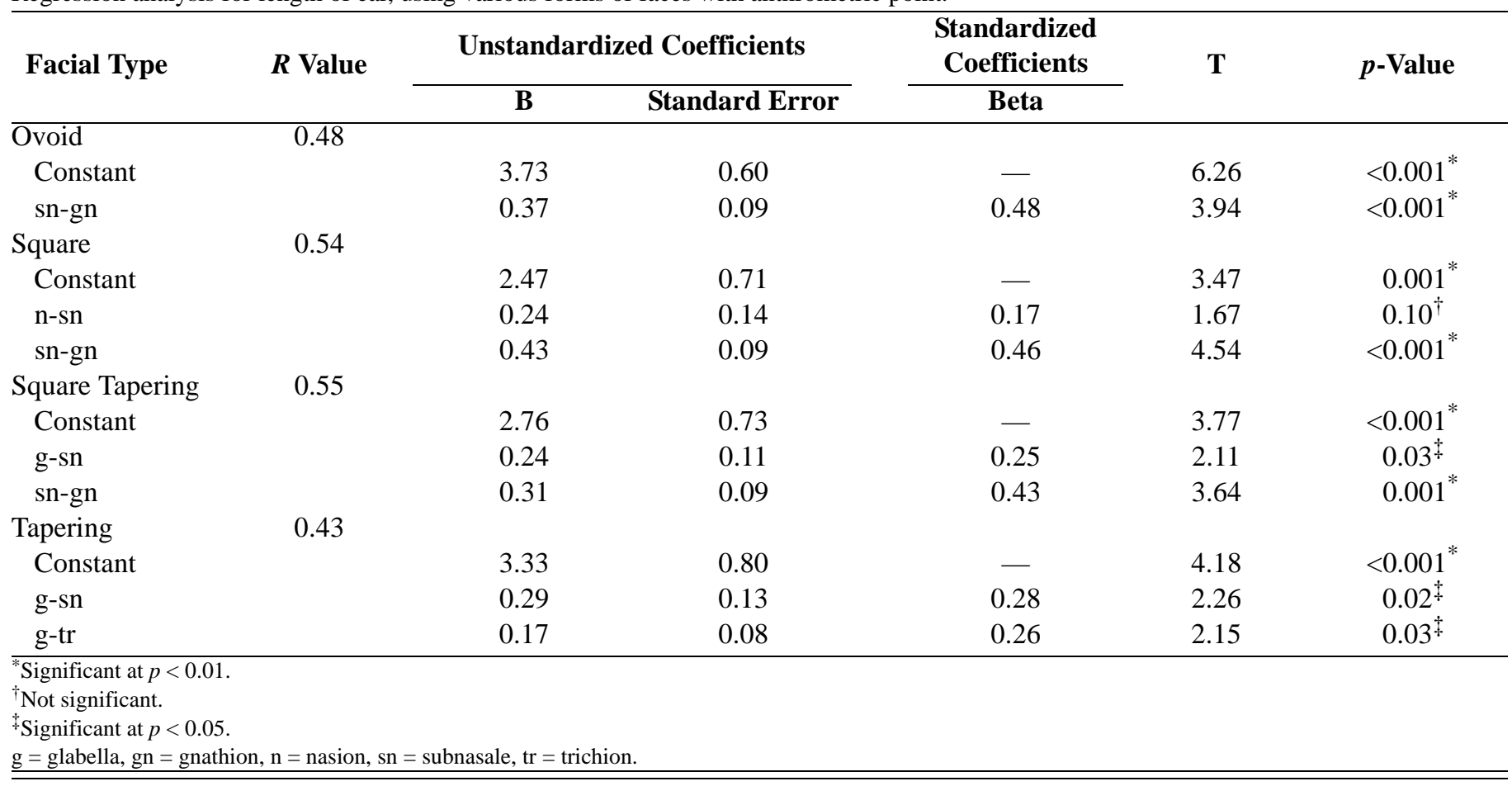

still relevant to use anthropometric measurement in plastic surgery and in the field of maxillofacial prosthetics. Previous research exists on siting ear prostheses accurately with the help of laser scanning in conjunction with computer-aided design/manufacturing [3]. Limited studies are available regarding siting ear prostheses with the guidance of anthropometric measurements coupled with a reference plane indicator. Similarly, information on making use of facial measurements to correlate with ear length and width, measuring ear visibility from the frontal view, and comparing the angulation of the ear with the nose is also limited.

Concerning superior-inferior position of the ear in relation to the reference plane, results obtained from crosstabulation analysis showed that the prosthetic ear can be positioned in the $\mathrm{B}$ and $\mathrm{E}$ categories in all facial forms. In this study, position of the subjects' head, operator's head, parallelism of first and second rulers in the reference plane indicator, and correct placement of the reference plane indicator on the face are essential for accurate results. In laser scanning technique as well, the 
Table 3.

Pearson correlation test for length of ear, $p<0.001$.

\begin{tabular}{|c|c|c|c|c|}
\hline Facial Type & n-sn & g-sn & g-tr & sn-gn \\
\hline \multicolumn{5}{|l|}{ Ovoid } \\
\hline Pearson $(r)$ & 0.32 & 0.28 & 0.29 & 0.48 \\
\hline$p$-Value & 0.02 & 0.03 & 0.03 & $<0.001$ \\
\hline \multicolumn{5}{|l|}{ Square } \\
\hline Pearson $(r)$ & 0.32 & 0.25 & 0.28 & 0.51 \\
\hline$p$-Value & 0.004 & 0.02 & 0.01 & $<0.001$ \\
\hline \multicolumn{5}{|l|}{ Square Tapering } \\
\hline Pearson $(r)$ & 0.37 & 0.37 & 0.34 & 0.50 \\
\hline$p$-Value & 0.01 & 0.004 & 0.01 & $<0.001$ \\
\hline \multicolumn{5}{|l|}{ Tapering } \\
\hline Pearson $(r)$ & 0.30 & 0.35 & 0.34 & 0.20 \\
\hline$p$-Value & 0.02 & 0.01 & 0.01 & 0.12 \\
\hline
\end{tabular}

Table 4.

Pearson correlation test for width of ear.

\begin{tabular}{lcc}
\hline \multicolumn{1}{c}{ Facial Type } & al-al & ex-en \\
\hline Ovoid & & 0.47 \\
$\quad$ Pearson $(r)$ & 0.45 & $<0.001$ \\
$p$-Value & 0.001 & \\
Square & & 0.56 \\
$\quad$ Pearson $(r)$ & 0.31 & 0 \\
$\quad p$-Value & 0.004 & \\
Square Tapering & & 0.61 \\
$\quad$ Pearson $(r)$ & 0.37 & 0 \\
$\quad p$-Value & 0.01 & \\
Tapering & & 0.64 \\
$\quad$ Pearson $(r)$ \\
$p$-Value
\end{tabular}

head should be oriented correctly within the scanning gantry to enable the scanner to digitize the location of the anthropometric points [3]. Moreover, if the image of the face is not oriented correctly, assessment of the position of the ear on the face with respect to the reference plane will be incorrect [3]. Though positioning of the reference plane is critical in both the studies, the present study appears to be simple and cost effective because of use of a reference plane. However, the present study is limited to positioning the ear superiorly-inferiorly only and not in a three-dimensional view.

For the ear length, regression analysis and Pearson correlation showed that the distance between subnasale
Table 5.

Descriptive statistics of various facial types: visibility of ear.

\begin{tabular}{lcccc}
\hline Visibility & $\begin{array}{c}\text { Ovoid } \\
\text { Face } \\
(\boldsymbol{n}=\mathbf{5 3 )}\end{array}$ & $\begin{array}{c}\text { Square } \\
\text { Face } \\
(\boldsymbol{n}=\mathbf{8 2})\end{array}$ & $\begin{array}{c}\text { Tapering } \\
\text { Face } \\
(\boldsymbol{n}=\mathbf{6 2})\end{array}$ & $\begin{array}{c}\text { Square } \\
\text { Tapering } \\
\text { Face } \\
(\boldsymbol{n}=\mathbf{5 7})\end{array}$ \\
\hline Minimum & 0.9 & 0.9 & 1.0 & 1.0 \\
Maximum & 2.4 & 2.1 & 2.5 & 2.0 \\
Mean \pm SD & $1.5 \pm 0.3$ & $1.5 \pm 0.3$ & $1.5 \pm 0.3$ & $1.5 \pm 0.4$ \\
\hline Note: Minimum is minimum visibility of ear from front (minimum ear protrusion). \\
Maximum is maximum visibility of ear from front (maximum ear protrusion). \\
SD = standard deviation. \\
\hline
\end{tabular}

Table 6.

Comparison of angulation of ear with nose (\%).

\begin{tabular}{lrrrrr}
\hline $\begin{array}{c}\text { Facial Form } \\
\text { and Ear } \\
\text { Angulation }\end{array}$ & $\begin{array}{c}\text { Ovoid } \\
\text { Face }\end{array}$ & $\begin{array}{c}\text { Square } \\
\text { Face }\end{array}$ & $\begin{array}{c}\text { Square } \\
\text { Tapering } \\
\text { Face }\end{array}$ & $\begin{array}{c}\text { Tapering } \\
\text { Face }\end{array}$ & Average \\
\hline Equal to Nose & 15.0 & 9.8 & 7.1 & 17.7 & 12.4 \\
Less than Nose & 83.0 & 90.2 & 92.9 & 82.3 & 87.1 \\
More than Nose & 2.0 & 0.0 & 0.0 & 0.0 & 0.5 \\
\hline \hline
\end{tabular}

and gnathion can be used as a predictable determinant for length of the ear in all facial forms except tapering faces. In the case of tapering faces, it is more accurate to use the glabella to trichion distance as a guide. Because of significance in regression and Pearson analysis, distances between nasion to subnasale and subnasale to glabella also can be used as a guide in the square and square tapering facial forms. According to Husein et al., the measurements of the lower face height (subnasale-gnathion) and midface height (glabella-subnasale) are almost equal to the length of the ear [2]. According to Porter and Olson, ear length is almost equal to forehead height (trichion-glabella) [1]. In the current study, for the width of the ear, the distances between exocanthion to endocanthion and interalar distance are the most predictable determinants for width of the ear. According to Ngeow and Aljunid, measurements of width of the ear are closer to eye fissures length [6].

The measurements used in the present study can be used as a guide for length and width of the prosthetic ear. Even though tools used in manual anthropometry distort the soft tissue and introduce error in measurements, manual anthropometry is still a commonly used technique because of its simplicity and because it is more economical [5]. Coward et al. reported that a difference of $5 \mathrm{~mm}$ in the length and 3 to $4 \mathrm{~mm}$ in the width of the ear were never perceivable to an observer [4]. Liu et al. compared the accuracy in the use of electronic digital caliper, photocopier 
scanner, and digital cameras to measure the length and width of the ear [12]. The analysis of variance revealed no significant differences in measurements between these devices. Ear dimensions by direct method, cast, computed tomography, magnetic resonance imagery, and laser scanning were compared, and the results revealed no significant differences in dimensions [4].The chief drawback of threedimensional photogrammetry is the cost of equipment required for the procedure, and two-dimensional photography cannot accurately measure curved surfaces [5]. Because of these findings, it would be more feasible and practical to use anthropometric measurements to determine length and width of the ear as compared with more technique-sensitive and expensive procedures.

Limited information is available regarding measurement of the visibility of the ear from the frontal view. Few studies have described the upper and lower protrusion from behind the ear. Based on the results of the current study, for all facial forms, ear visibility is approximately $1.5 \mathrm{~cm}$ in upper protrusion. According to Driessen et al., upper protrusion should not exceed more than $21.5 \mathrm{~mm}$ in males and $17.5 \mathrm{~mm}$ in females [13]. Lower protrusion should not exceed more than $20.0 \mathrm{~mm}$ in males and $15.5 \mathrm{~mm}$ in females. Upper protrusion plays a more important role in the perception of prominence as compared with lower protrusion [13].

According to the current study, a greater percentage of individuals show ear inclination less than nose inclination in all the facial forms. Porter and Olson [1], Husein et al. [2], and Choe et al. [14] found that the ear inclination is always less than the nasofacial angle. Based on the available literature and current results, while designing ear prosthesis it is preferable to keep the angulation of the ear less than that of the nose.

\section{CONCLUSIONS}

The challenge of restoring to normalcy patients with bilaterally missing ears can be significantly reduced by simple anthropometric measurements. Although technology has advanced and newer techniques are available, anthropometric measurements offer successful outcomes while determining the positioning, dimensions, visibility, and angulation of the ear prosthesis. From the present study, we were able to conclude that the subnasale to gnathion distance was the most dependent variable with respect to the length of the ear, while both interalar dis- tance and exocanthion to endocanthion distance correlate highly significantly to the width of the ear. While considering the position of the ear, in all facial forms except the square tapering facial form, the maximum number of samples showed highest frequency for the subaurale in line with subnasale. In all subjects, the visibility of the ear when viewed from the front was an average of $1.5 \mathrm{~mm}$. Regardless of facial form, ear angulation was generally less than that of nose angulation. This study was specific to a Southeast Asian population, and variations may be seen based on the ethnicity of the individual. Further studies are necessary in this regard.

\section{ACKNOWLEDGMENTS}

\section{Author Contributions:}

Study concept and design: K. Mohamed.

Acquisition of data: K. Mohamed, J. Christian, K. Jeyapalan, S. Natarajan. Analysis and interpretation of data: K. Mohamed, F. Banu.

Drafting of manuscript: K. Mohamed, J. Christian, F. Banu.

Critical revision of manuscript for important intellectual content: K. Mohamed.

Statistical analysis: K. Mohamed, F. Banu.

Administrative, technical, or material support: K. Mohamed, J. Christian, K. Jeyapalan, S. Natarajan.

Study supervision: K. Mohamed, P. Veeravalli.

Financial Disclosures: The authors have declared that no competing interests exist.

Funding/Support: This work was unfunded at time of manuscript preparation.

Institutional Review: Ethical consent was obtained from the institutional ethical committee of Sri Ramachandra University prior to starting this study. Informed consent was obtained from all subjects.

\section{REFERENCES}

1. Porter JP, Olson KL. Anthropometric facial analysis of the African American woman. Arch Facial Plast Surg. 2001; 3(3):191-97. [PMID:11497505]

http://dx.doi.org/10.1001/archfaci.3.3.191

2. Husein OF, Sepehr A, Garg R, Sina-Khadiv M, Gattu S, Waltzman J, Wu EC, Shieh M, Heitmann GM, Galle SE. Anthropometric and aesthetic analysis of the Indian American woman's face. J Plast Reconstr Aesthet Surg. 2010; 63(11):1825-31. [PMID:19962360] http://dx.doi.org/10.1016/j.bjps.2009.10.032

3. Coward TJ, Scott BJ, Watson RM, Richards R. Identifying the position of an ear from a laser scan: The significance for planning rehabilitation. Int J Oral Maxillofac Surg. 
2002;31(3):244-51. [PMID:12190128]

http://dx.doi.org/10.1054/ijom.2001.0152

4. Coward TJ, Scott BJ, Watson RM, Richards R. A comparison between computerized tomography, magnetic resonance imaging, and laser scanning for capturing 3dimensional data from a natural ear to aid rehabilitation. Int J Prosthodont. 2006;19(1):92-100. [PMID:16479767]

5. Ozkul T, Ozkul MH, Akhtar R, Al-Kaabi F, Jumaia T. A software tool for measurement of facial parameters. Open Chem Biomed Meth J. 2009;2:69-71. http://dx.doi.org/10.2174/1875038900902010069

6. Ngeow WC, Aljunid ST. Craniofacial anthropometric norms of Malays. Singapore Med J. 2009;50(5):525-28. [PMID:19495526]

7. Ferrario VF, Sforza C, Ciusa V, Serrao G, Tartaglia GM. Morphometry of the normal human ear: A cross-sectional study from adolescence to mid-adulthood. J Craniofac Genet Dev Biol. 1999;19(4):226-33. [PMID:10731092]

8. Heartwell CM, Rahn AO. Syllabus of complete dentures. 4th ed. Philadelphia (PA): Lea \& Febiger; 1986.

9. Sforza C, Grandi G, Binelli M, Tommasi DG, Rosati R, Ferrario VF. Age- and sex-related changes in the normal human ear. Forensic Sci Int. 2009;187(1-3):e1-7. [PMID:19356871] http://dx.doi.org/10.1016/j.forsciint.2009.02.019

10. Jung HS, Jung HS. Surveying the dimensions and characteristics of Korean ears for the ergonomic design of ear related products. Int J Ind Ergon. 2003;31:361-73. http://dx.doi.org/10.1016/S0169-8141(02)00237-8

11. Barut C, Aktunc E. Anthropometric measurements of the external ear in a group of Turkish primary school students.
Aesthetic Plast Surg. 2006;30(2):255-59.

[PMID:16547632]

http://dx.doi.org/10.1007/s00266-005-0182-1

12. Liu BS, Tseng HY, Chia TC. Reliability of external ear measurements obtained by direct, photocopier scanning and photo anthropometry. IEMS. 2010;9:20-27.

13. Driessen JP, Borgstein JA, Vuyk HD. Defining the protruding ear. J Craniofac Surg. 2011;22(6):2102-8.

[PMID:22067874] http://dx.doi.org/10.1097/SCS.0b013e3182326dfb

14. Choe KS, Sclafani AP, Litner JA, Yu GP, Romo T 3rd. The Korean American woman's face: Anthropometric measurements and quantitative analysis of facial aesthetics. Arch Facial Plast Surg. 2004;6(4):244-52. [PMID:15262719] http://dx.doi.org/10.1001/archfaci.6.4.244

Submitted for publication June 17, 2013. Accepted in revised form December 3, 2013.

This article and any supplementary material should be cited as follows:

Mohamed K, Christian J, Jeyapalan K, Natarajan S, Banu F, Veeravalli PT. Identifying position, visibility, dimensions, and angulation of the ear. J Rehabil Res Dev. 2014; 51(4):599-608.

http://dx.doi.org/10.1682/JRRD.2013.06.0132

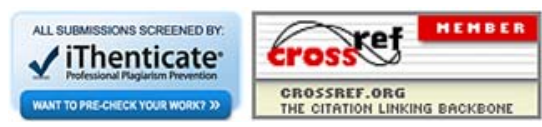


